\title{
Association between Heavy Metals and Rare Earth Elements with Acute Ischemic Stroke: A Case-Control Study Conducted in the Canary Islands (Spain)
}

\author{
Florián Medina-Estévez ${ }^{1}$, Manuel Zumbado ${ }^{2}{ }^{\circledR}$, Octavio P. Luzardo ${ }^{2}(\mathbb{D}$, \\ Ángel Rodríguez-Hernández ${ }^{2}$, Luis D. Boada ${ }^{2}$, Fernando Fernández-Fuertes ${ }^{1}$, \\ María Elvira Santandreu-Jimenez ${ }^{1}$ and Luis Alberto Henríquez-Hernández ${ }^{2, * \mathbb{D}}$ \\ 1 Rehabilitation Service, Complejo Hospitalario Insular-Materno Infantil (CHUIMI), \\ Avenida Marítima del Sur, 35016 Las Palmas de Gran Canaria, Spain; florianmed@gmail.com (F.M.-E.); \\ fferfue@gobiernodecanarias.org (F.F.-F.); maviras@yahoo.es (M.E.S.-J.) \\ 2 Toxicology Unit, Research Institute of Biomedical and Health Sciences (IUIBS), \\ Department of Clinical Sciences, Universidad de Las Palmas de Gran Canaria (ULPGC), \\ Paseo Blas Cabrera Felipe s/n, 35016 Las Palmas de Gran Canaria, Spain; manuel.zumbado@ulpgc.es (M.Z.); \\ octavio.perez@ulpgc.es (O.P.L.); anrodrivet@gmail.com (Á.R.-H.); luis.boada@ulpgc.es (L.D.B.) \\ * Correspondence: luis.henriquez@ulpgc.es
}

Received: 7 August 2020; Accepted: 31 August 2020; Published: 2 September 2020

\begin{abstract}
The role of inorganic elements as risk factors for stroke has been suggested. We designed a case-control study to explore the role of 45 inorganic elements as factors associated with stroke in 92 patients and 83 controls. Nineteen elements were detected in $>80 \%$ of patients and 21 were detected in $>80 \%$ of controls. Blood level of lead was significantly higher among patients (11.2 vs. $9.03 \mathrm{ng} / \mathrm{mL}$ ) while gold and cerium were significantly higher among controls $(0.013 \mathrm{vs} .0 .007 \mathrm{ng} / \mathrm{mL}$; and 18.0 vs. $15.0 \mathrm{ng} / \mathrm{mL}$ ). Lead was associated with stroke in univariate and multivariate analysis $(\mathrm{OR}=1.65$ (95\% CI, 1.09-2.50) and OR = 1.91 (95\% CI, 1.20-3.04), respectively). Gold and cerium showed an inverse association with stroke in multivariate analysis (OR $=0.81$ (95\% CI, 0.69-0.95) and OR $=0.50(95 \% \mathrm{CI}, 0.31-0.78)$ ). Future studies are needed to elucidate the potential sources of exposure and disclose the mechanisms of action.
\end{abstract}

Keywords: stroke; cerebrovascular accident; heavy metal; rare earth element; case-control study

\section{Introduction}

Ischemic stroke is a sudden disorder of cerebral blood flow that temporarily or permanently alters the function of a certain region of the brain. According to the World Stroke Organization (WSO), age-adjusted rate for ischemic stroke per 100,000 populations was 142.34 in 2016. Over 9.5 million new cases were diagnosed during that year [1]. Prevalence of stroke in US population younger than 60 years old is around $2 \%$, but this proportion rises to $6 \%$ and $15 \%$ in people older than 60 and 80 years old, respectively [2]. In Spain, it has been estimated a prevalence of stroke of $6.4 \%$ in subjects older than 70 years [3].

Age-adjusted incidence ranges from 50 to 250 per 100,000 populations in France and Portugal, respectively [4]. In our country, for a similar period, incidence ranged from 99 to 206 per 100,000 populations, depending on the region in which the study was conducted [4]. The Canary Islands are the second region of Spain with the lowest adjusted rate of stroke (25.33 per 100,000 men and 19.66 per 100,000 women) [3].

Stroke is the second leading cause of death worldwide, and the third leading cause of disability [5]. In Spain, mortality has decreased considerably during the past decades, standing at around 50 per 
100,000 inhabits for both sexes [6]. The Canary Islands are the second autonomous community in Spain with the lowest adjusted rate of cerebrovascular deaths (25.3 per 100,000 males and 19.7 per 100,000 women) [3].

The main risk factors for stroke are mostly modifiable factors such as hypertension, dyslipidemia, diabetes, smoking, low physical activity levels, unhealthy diet and abdominal obesity [2]. Age, gender, race/ethnicity or genetics also have an important role for the disease [7]. New risk factors for stroke have been proposed during the last decades. Some of them have emerged as protective factors (i.e., antiplatelet therapy) while others seem to increase the risk of stroke (i.e., sleep apnea or lipoprotein levels) [2]. However, their contribution to stroke risk is less well defined and understood. This is the case of environmental pollutants. In addition to gaseous and particulate air pollutants [8], persistent organic pollutants (POPs) seem to play an important role in development of stroke [9]. Although the association had been seen for years, it has recently been observed that elevated serum POPs levels were associated with an increased risk of stroke, specifically for organochlorine pesticides ( $\left.p, p^{\prime}-D D E\right)$ and polychlorinated biphenyls (PCB-118, -156 and -138) [10], possibly due to an association with hypertension [11,12] and obesity [13].

Among environmental pollutants, toxic heavy metals and metalloids are among the most dangerous because they are also not biodegradable and tend to accumulate in environmental compartments [14]. According to their high degree of toxicity, arsenic, cadmium, lead and mercury are usually highlighted among others [14]. However, the Agency for Toxic Substances and Disease Registry (ATSDR) publishes a list of priority chemicals that are determined to represent the most significant potential threat to human health because of their known or suspected toxicity, together with the potential human exposure. Additionally, there are a number of elements, the rare earth elements (REE) and other minor elements (ME), which are increasingly coveted due to the large number of technological applications for which they are already indispensable [15]. This set of elements is of growing concern because its enormous range of applications makes them mobilized from the few sites where they are abundant to be distributed all over the planet [16], especially once the useful life of the devices containing them ends. Although some of these elements are relatively abundant in the Earth's crust (i.e., cerium is as abundant as copper), REEs have been included among the new and emerging occupational and environmental health risks by several international organizations [17]. Different studies have shown that some of these elements have an adverse effect on people's health [18-20], although the mechanisms of action are not clear $[17,21]$.

Of all these inorganic elements, arsenic and lead have shown a relationship with stroke [22-25]. A significant dose-response relationship was observed between arsenic concentration in well water and prevalence of cerebrovascular disease [25] and a positive trend was reported between blood lead and stroke in a series of 88,000 workers from USA, Finland and UK [24]. However, the mechanisms of action are not clear and, for example, a potential role for arsenic methylation in the pathogenesis of stroke has been suggested [22].

It has to be highlighted that some inorganic elements are neurological disruptors with the capacity to cross the blood brain barrier [18]. While small concentrations of some elements are needed for life, most are considered non-essential and some are very toxic even at very low concentrations. Some elements follow a hormetic dose-response curve and may cause, at a very low dose, the opposite effect to a high dose [26]. Thus, the presence of these elements into neurons, even at low concentrations, seems to be able to modify brain homeostasis. This is the case of gadolinium and tantalum whose tissue concentrations were higher among patients with brain cancer compared to a control group [18]. The aim of the present study was to evaluate the contribution of 45 inorganic elements-including trace elements, elements included in the priority list of substances of the Agency for Toxic Substances and Disease Registry (ATSDR), and REE and other elements used in electronic devices-as factors associated with stroke. 


\section{Patients and Methods}

\subsection{Study Design and Participants}

We designed a case-control study aimed to disclose the role of inorganic elements in the stroke. The study was approved by the Research Ethics Committee of the CHUIMI on 23 February 2017 (ID number: CEIm-CHUIMI-2017/907). For that, a total of 92 patients diagnosed with ischemic stroke and admitted into the Complejo Hospitalario Insular-Materno Infantil CHUIMI for rehabilitation were included in the study. The control group consisted of patients admitted to the rehabilitation service for other causes. The final number of control subjects was 83 . The recruitment was made between April 2017 and April 2018. The inclusion criteria for cases were: (i) having been diagnosed of stroke in the 12 months prior to being referred to the Rehabilitation Service, (ii) ability to agree to participate in the study (signed informed consent) and (iii) being over 18 years old. The inclusion criteria for controls were: (i) admission diagnosis unrelated with stroke (i.e., traumatic diseases), (ii) never having been diagnosed with stroke, (iii) ability to agree to participate in the study (signed informed consent) and (iv) being over 18 years. Cases and controls were matched in terms of age and gender making a selection of cases in relation to the demographic characteristics of the cases.

Patients—cases and controls—were contacted and asked to participate in the study. All patients signed the informed consent before entering the study. The study was approved by the Research Ethics Committee of the CHUIMI (study number CEIm-CHUIMI-2017/907).

Barthel index, an instrument widely used to evaluate independency and measures the capacity of the person for the execution of ten basic activities in daily life [27], was recorded three months after the admission in the rehabilitation service. The demographic and clinical data of the patients included in the study were collected from the corresponding medical records and are shown in Table 1.

Table 1. Demographic characteristics of study participants.

\begin{tabular}{|c|c|c|c|}
\hline & Cases $N(\%)$ & Controls N (\%) & $p$-Value \\
\hline All participants & $92(52.6)$ & $83(47.4)$ & \\
\hline \multicolumn{4}{|l|}{ Gender } \\
\hline Male & $47(51.1)$ & $43(51.8)$ & $0.924^{\mathrm{a}}$ \\
\hline Female & $45(48.9)$ & $40(48.2)$ & \\
\hline \multicolumn{4}{|l|}{ Age (years) } \\
\hline Mean \pm SD & $64.1 \pm 12.7$ & $61.7 \pm 14.8$ & $0.472^{b}$ \\
\hline Median & 64 & 65 & \\
\hline Range & $34-87$ & $33-86$ & \\
\hline Smoker (yes) & $31(33.7)$ & $14(16.9)$ & $0.015^{\mathrm{a}}$ \\
\hline Diabetes (yes) & $25(27.2)$ & $29(34.9)$ & $0.326^{\mathrm{a}}$ \\
\hline Arterial hypertension (yes) & $61(66.3)$ & $28(33.7)$ & $<0.0001^{\mathrm{a}}$ \\
\hline Dyslipidemia (yes) & $61(66.3)$ & $30(36.1)$ & $<0.0001^{\mathrm{a}}$ \\
\hline Coronary cardiopathy (yes) & $30(32.6)$ & $13(15.7)$ & $0.013^{a}$ \\
\hline \multicolumn{4}{|l|}{ Barthel index } \\
\hline Mean \pm SD & $67.2 \pm 32.7$ & $93.2 \pm 16.9^{c}$ & $<0.0001^{b}$ \\
\hline Median & 75 & 100 & \\
\hline 0-60 (severe dependence) & $38(41.3)$ & $9(11.0)$ & $<0.0001^{a}$ \\
\hline 61-90 (moderate dependence) & $20(21.7)$ & $6(7.3)$ & \\
\hline$>90$ (poor dependence/Independence) & $34(37.0)$ & $67(81.7)$ & \\
\hline
\end{tabular}

Blood samples were obtained from all of the participants. Samples of blood were collected in $4 \mathrm{~mL}$ heparinized tubes (BD Vacutainer, LH 68 I.U. Lithium Heparin, BD-Plymouth, PL6 7BP, UK) and maintained at $4{ }^{\circ} \mathrm{C}$. An aliquot of blood was stored at $-80^{\circ} \mathrm{C}$ until the chemical analysis, performed in the Toxicology Unit of the ULPGC. 


\subsection{Selection of Elements and Sample Preparation}

Blood concentration levels of 45 inorganic elements were analyzed. We determined trace elements, heavy metals, rare earth elements (REEs) and other elements used in electronic devices, as we have previously reported $[15,28]$.

Then, $100 \mathrm{mg}$ of whole blood was weighed into quartz digestion tubes and then digested into $1 \mathrm{~mL}$ of acid solution $\left(65 \% \mathrm{HNO}_{3}\right)$ using a Milestone Ethos Up equipment (Milestone, Bologna, Italy). The digestion conditions were programmed as follows (power $(\mathrm{W})$-temperature $\left({ }^{\circ} \mathrm{C}\right)$-time (min): step 1: 1800-100-5; step 2: 1800-150-5; step 3: 1800-200-8; and step 4: 1800-200-7. After cooling, the digested samples were transferred and diluted. An aliquot of each sample was taken and the internal standard (ISTD) was added for the analysis.

The ISTD solution included scandium, germanium, rhodium and iridium $(20 \mathrm{mg} / \mathrm{mL}$ each). Elements of standard purity $\left(5 \% \mathrm{HNO}_{3}, 100 \mathrm{mg} / \mathrm{L}\right)$ were purchased from CPA Chem (Stara Zagora, Bulgaria). Two standard curves (range $=0.005-20 \mathrm{ng} / \mathrm{mL}$ ) were made: (a) one used a commercial multi-element mixture (CPA Chem Catalog number E5B8·K1.5N.L1, 21 elements) containing all the trace elements and the main heavy metals and (b) the other multi-element mixture included individual elements (CPA Chem) that contained the REEs and other elements used in electronic devices [18,19].

\subsection{Analytical Procedure}

An Agilent 7900 ICP-MS (Agilent Technologies, Tokyo, Japan) was used for quantification. Instrument configuration and optimization were previously reported [18]. The elements were quantified in the MassHunter v.4.2. ICP-MS Data Analysis software (Agilent Technologies).

The analytical method was previously validated [29]. The recoveries rates were $89-128 \%$ for REEs and other elements used in electronic devices, and 87-118\% for ATSDR's toxic heavy elements and trace elements (regression coefficients $>0.998$ for all elements). The limit of quantification (LOQ) was calculated by quantifying 6 replicates of blanks, consisting in $0.130 \mu \mathrm{L}$ of alkaline solution, as the concentration of the element that produced a signal three times higher than that of the averaged blanks (Supplementary Materials 1). The accuracy and precision were assessed by substituting the sample with a fortified alkaline solution $(0.05,0.5$ and $5 \mathrm{ng} / \mathrm{mL})$. The calculated relative standard deviations (RSD) were lower than $8 \%$, except for copper, nickel, selenium, iron, barium, zinc and samarium. However, at the lowest level of fortification, the RSD was higher than $15-16 \%$.

\subsection{Statistical Analysis}

Descriptive analyses were conducted for all of the variables. Medians, ranges and the 5th-95th percentiles of the distribution were calculated for continuous variables. Proportions were calculated for categorical variables. Values below the LOQ were assigned a random value between 0 and the LOQ [18,30]. For this, a specific computational function was used (Microsoft Excel (2010), RANDBETWEEN function).

The normality of the data was assessed using the Kolmogorov-Smirnov test. Since most of the data (concentrations of elements) did not follow a normal distribution, comparisons between groups were performed using non-parametric tests (Kruskal-Wallis and Mann-Whitney U-test). Differences in the categorical variables were tested with the Chi-square test. The correlation of inorganic elements with continuous variables (age and Barthel index) was analyzed with Pearson's correlation test. Bivariate correlations among elements were done with Spearman's rho test. Univariate and multivariate analyses were done with logistic regression test. For multivariate logistic regression analysis, smoking, arterial hypertension, dyslipidemia and coronary cardiopathy were included as covariates. These variables were specifically included because they showed to be a significant risk factor for stroke in the present series (Figure 1). Values of elements were log transformed before the inclusion in logistic regression analyses. We used PASW Statistics v 19.0 (SPSS Inc., Chicago, IL, USA) to manage the database 
and to perform the statistical analyses. Probability levels of $<0.05$ (two-tailed) were considered statistically significant.

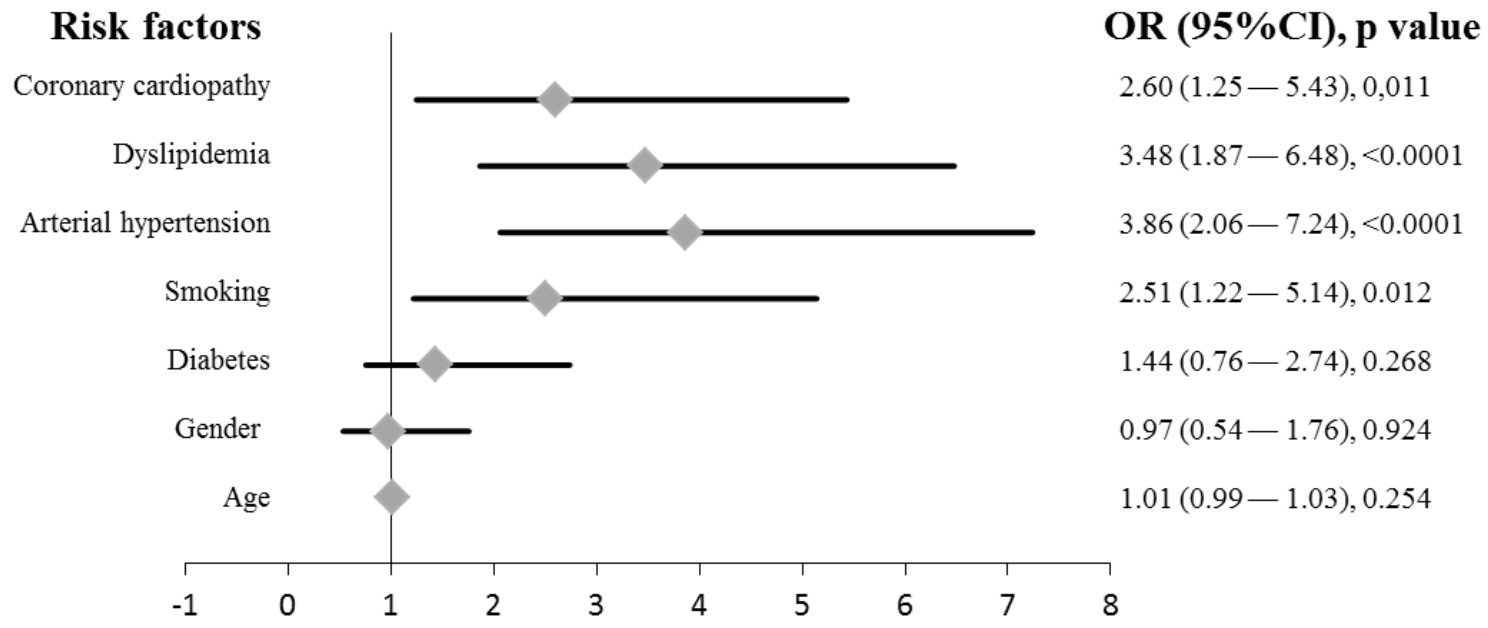

Figure 1. Forrest plot of odds ratios (ORs) with $95 \%$ confidence interval (CI) for factors associated with stroke. Each diamond represents the OR and the horizontal line indicates the $95 \%$ CI. For the binary logistic regression, patients were dichotomized into two groups as follows: patients who suffered stroke vs. patients who did not suffer the disease.

\section{Results and Discussion}

A total of 45 inorganic elements were measured. To better understand the main results, elements were separated into two different categories: (i) trace elements and inorganic elements included in the ATSDR's priority pollutant list, which includes heavy metal and other well-known toxic elements [28]; and (ii) RREs and other elements employed in the manufacture of electronic devices [15].

\subsection{Clinical Characteristics of Cases and Controls}

A total of 92 patients, admitted into the Rehabilitation Service after suffering a stroke, and 83 control patients were included in the study. No significant differences were detected in age and gender distribution (Table 1). Although it has been published that three quarters of strokes occur in patients over 65 [6], we observed that this proportion was 50.0\% in our series (Data not shown).

The distribution of the main clinical factors associated to the stroke [7] were significantly different among cases and controls, with the exception of diabetes. Smoking, arterial hypertension, dyslipidemia and coronary cardiopathy appeared associated with stroke (Figure 1). We observed that hypertension was the factor that showed the highest significance (odds ratio (OR) $=3.86$ (confidence interval (CI) $95 \%$, 2.06-7.24), $p$-value < 0.0001; univariate analysis), as previously established [7]. Regarding diabetes, it has been published a 2-fold increased risk in stroke for diabetic patients, and stroke accounts for approximately $20 \%$ of deaths in diabetics [7]. However, we did not observe this trend in our series. Canary Islands have one of the highest ratios of diabetes in Spain [31]. In that sense, while 27.2\% of cases were diabetics, this proportion was higher (34.9\%) among controls (Table 1 ). This pattern of distribution makes difficult to observe the role of diabetes in our study population. Cigarette smoking remains a major factor for stroke [32]. We absolutely agree with that observation and an $\mathrm{OR}=2.51$ (Figure 1) was observed in the present series.

Mean value of Barthel index was 67.8 and 93.2 among cases and controls, respectively $(p<0.0001$, Mann-Whitney U-test), and $41.3 \%$ of patients who suffered a stroke showed a severe dependence (Table 1). This profile is similar to other studies focused in the evaluation of disability after a stroke [33]. 


\subsection{ATSDR's Priority Elements in Stroke}

A total of 19 inorganic elements including in the ATSDR's priority pollutant list [28] were analyzed in the whole blood of cases and controls. Serum is the matrix of choice for the determination of inorganic elements, mainly for trace elements whose reference values are those of the serum. However, in an effort to prioritize the toxic elements whose presence is mostly found in blood cells (i.e., lead or mercury), whole blood was the matrix of study [18]. We observed a high frequency of detection in both groups, where most of the elements were present in more than $75 \%$ of the series (Table 2 ). The less frequently detected elements were beryllium in the control group $(8.4 \%)$, and palladium among stroke patients $(9.8 \%)$.

In general, we do not observe any influence of age on the distribution of these elements, with the exception of antimony and thorium that showed a significant positive correlation in cases and controls (Pearson's $r=0.26, p$-value $=0.012$ and Pearson's $r=0.24, p$-value $=0.026$, respectively; Supplementary Materials 2). Among patients in the control group, women presented slightly higher levels of silver, cadmium, cobalt, copper, manganese, strontium and uranium; however, among cases, this list was reduced to beryllium, cobalt and copper (Supplementary Materials 3). Since age did not seem to be a determining factor for the accumulation of these substances, these differences could be attributable to other environmental factors such as diet or unhealthy habits [34-37]. However, although it is known that the smoking habit is a source of exposure of inorganic elements, we do not observe this trend in our series (Supplementary Materials 3), possibly due to the low proportion of smokers (25.7\% of the series was smoker) and the lack of determining covariates such as the intensity of the habit or its duration [38].

Among the 19 inorganic elements included in the ATSDR's priority pollutant list, 2 of them had a higher blood concentration among cases (beryllium and lead); and 2 showed higher blood concentration among the controls (barium and uranium). Of these 4 elements, 3 (barium, lead and uranium) were detected in $100 \%$ of the subjects. Given the low frequency of detection, the result referring to beryllium should be taken with caution (Table 2). In univariate analysis, barium and lead were significantly associated with stroke $(\mathrm{OR}=0.34,95 \%$ CI 0.19-0.60, $p$-value $<0.001$; and OR = 1.65, 95\% CI 1.09-2.50, $p$-value $=0.019$, respectively; Table 3). No significant results were observed for uranium (Data not shown). In multivariate analysis, barium and lead kept their significant tendency (Table 3).

Neither of these two elements (barium or lead) were significantly influenced by any of the known risk factors for stroke. That is, neither in the case group nor in the group of controls, was barium or lead differentially affected by diabetes, dyslipidemia, smoking or the presence of arterial hypertension (Supplementary Materials 3). From this it follows that both elements can be considered independent factors associated with stroke, something plausible given the capacity of these substances to cross the blood-brain barrier and, therefore, exert an effect on brain tissue [18]. The role that inorganic elements have in relation to stroke has been studied, above all, in relation to heavy metals and major metalloids, with disparate and, sometimes, contradictory results [39]. It has to be taken into account that some toxic elements have been associated to well-known risk factors for stroke, establishing an indirect association with the disease. This is the case of arsenic, lead and specific RREs found in indoor air pollution affecting the risk of suffering hypertension [40]; or the case of arsenic, lead, cadmium and copper, whose exposure is associated with an increased risk of cardiovascular disease [23,41].

Arsenic has been previously associated with stroke [42]. In the present study, no significant differences were observed regarding to the blood concentration of arsenic among cases and controls (Table 2), possible due to the limit size of our series. Wen et al. (2019) reported median values of arsenic —among 1277 cases and 1277 controls_of 1.48 and $1.18 \mathrm{ng} / \mathrm{mL}$, respectively [42], being significant that subtle difference of concentration. In our series, median values of arsenic were 1.61 and $1.69 \mathrm{ng} / \mathrm{mL}$ among 92 cases and 83 controls, respectively ( $p$-value $=0.546$; Table 2 ). 
Table 2. Blood concentration $(\mathrm{ng} / \mathrm{mL})$ of inorganic elements including in the ATSDR's priority pollutant list (2017) ${ }^{\mathrm{a}}$, among cases and controls.

\begin{tabular}{|c|c|c|c|c|c|c|c|}
\hline & \multicolumn{3}{|c|}{ Controls $(n=83)$} & \multicolumn{3}{|c|}{ Cases $(n=92)$} & \multirow[b]{2}{*}{$p$-Value } \\
\hline & Frequency of Detection (\%) & Median & (p5th-p95th) & Frequency of Detection (\%) & Median & (p5th-p95th) & \\
\hline Ag (silver) & 79.5 & 0.006 & $(0-0.37)$ & 80.4 & 0.064 & $(0-0.29)$ & 0.429 \\
\hline As (arsenic) & 100 & 1.69 & $(0.45-7.74)$ & 100 & 1.61 & $(0.38-5.50)$ & 0.546 \\
\hline Ba (barium) & 100 & 207.0 & $(111.9-669.3)$ & 100 & 173.5 & $(96.3-324.8)$ & $<0.0001$ \\
\hline Be (beryllium) & 8.4 & 0.002 & $(0-0.20)$ & 12.0 & 0.005 & $(0-0.57)$ & 0.006 \\
\hline $\mathrm{Cd}$ (cadmium) & 100 & 0.25 & $(0.09-1.32)$ & 100 & 0.26 & $(0.12-1.06)$ & 0.359 \\
\hline Co (cobalt) & 97.6 & 0.19 & $(0.11-0.38)$ & 100 & 0.19 & $(0.11-0.45)$ & 0.742 \\
\hline $\mathrm{Cu}\left(\right.$ copper) ${ }^{\mathrm{c}, \mathrm{d}}$ & 100 & 0.60 & $(0.42-0.89)$ & 100 & 0.62 & $(0.49-0.80)$ & 0.293 \\
\hline $\mathrm{Hg}$ (mercury) & 98.8 & 3.74 & $(1.01-17.4)$ & 100 & 3.65 & $(0.92-11.9)$ & 0.793 \\
\hline Mn (manganese) ${ }^{c}$ & 96.4 & 8.48 & $(0.16-14.5)$ & 97.8 & 7.85 & $(4.55-16.8)$ & 0.591 \\
\hline Ni (nickel) & 92.8 & 1.08 & $(0.048-52.6)$ & 93.5 & 0.98 & $(0.052-76.5)$ & 0.534 \\
\hline $\mathrm{Pb}$ (lead) & 100 & 9.03 & $(4.21-20.0)$ & 100 & 11.2 & $(4.01-25.3)$ & 0.011 \\
\hline Pd (palladium) & 19.3 & 0.002 & $(0-0.083)$ & 9.8 & 0.004 & $(0-0.25)$ & 0.352 \\
\hline Se (selenium) ${ }^{c}$ & 100 & 126.1 & (73.0-205.3) & 100 & 128.3 & $(79.6-169.2)$ & 0.589 \\
\hline $\mathrm{Sb}$ (antimony) & 33.7 & 0.027 & $(0.003-1.14)$ & 26.1 & 0.022 & $(0.002-1.31)$ & 0.151 \\
\hline Sr (strontium) & 100 & 16.6 & $(11.2-25.0)$ & 100 & 15.4 & $(9.93-28.7)$ & 0.101 \\
\hline Th (thorium) & 92.8 & 0.071 & $(0.001-0.22)$ & 89.1 & 0.061 & $(0.001-0.12)$ & 0.082 \\
\hline U (uranium) & 100 & 0.082 & $(0.051-0.21)$ & 100 & 0.072 & $(0.037-0.16)$ & 0.024 \\
\hline V (vanadium) & 59.0 & 0.011 & $(0.001-0.44)$ & 35.9 & 0.008 & $(0-0.56)$ & 0.221 \\
\hline Zn (zinc) ${ }^{c, d}$ & 100 & 5.13 & $(3.7-8.06)$ & 100 & 5.29 & $(3.77-6.53)$ & 0.652 \\
\hline
\end{tabular}

${ }^{a}$ Complete list available at https://www.atsdr.cdc.gov/spl/. ${ }^{b}$ Mann-Whitney U test (two tails). ${ }^{c}$ Also considered as trace elements. ${ }^{d}$ Data reported in $\mu \mathrm{g} / \mathrm{mL}$. 
Table 3. Inorganic elements significantly associated with stroke.

\begin{tabular}{cccc}
\hline Element & Odds Ratio & $\mathbf{9 5 \% ~ C I ~}$ & $p$-Value ${ }^{\text {a }}$ \\
\hline Univariate analyses & & & \\
\hline Ba (barium) & 0.34 & $(0.19-0.60)$ & $<0.001$ \\
Pb (lead) & 1.65 & $(1.09-2.50)$ & 0.019 \\
Au (gold) & 0.81 & $(0.70-0.95)$ & 0.007 \\
Ce (cerium) & 0.61 & $(0.42-0.90)$ & 0.012 \\
Ga (gallium) & 0.64 & $(0.46-0.88)$ & 0.007 \\
\hline Multivariate analyses & & & \\
\hline Ba (barium) & 0.28 & $(0.15-0.55)$ & $<0.001$ \\
Pb (lead) & 1.91 & $(1.20-3.04)$ & 0.006 \\
Au (gold) & 0.81 & $(0.69-0.95)$ & 0.011 \\
Ce (cerium) & 0.50 & $(0.31-0.78)$ & 0.003 \\
Ga (gallium) & 0.58 & $(0.40-0.86)$ & 0.006 \\
\hline
\end{tabular}

a $p$-values were calculated by binary logistic regression. Inorganic elements are log transformed and included in the models as continuous variables. For multivariate analyses, smoking, arterial hypertension, dyslipidemia and coronary cardiopathy are included as covariables.

Lead was associated with stroke in univariate and multivariate analysis (Table 3). In that sense, lead-exposed workers showed higher mortality rate by stroke-and other diseases, a result that supports those obtained in the present study [24]. The association of ischemic stroke and lead has been shown in other studies [41,43]. However, other studies did not report any association between lead—or arsenic—and stroke [39]. Reference values (RV95s) for arsenic and lead are 2.0 and $33 \mathrm{ng} / \mathrm{mL}$, respectively, for adult population [44]. In the present series, 35.9\% $(n=33)$ and $39.8 \%(n=33)$ of cases and controls, respectively, showed values of arsenic higher than RV95s (Chi-square test, $p=0.641$; data not shown). Nobody was above RV95s for lead. This profile of distribution of elements is similar to the general population of Spain [45].

Previous publications have observed that the levels of certain inorganic elements are higher in the control group than among stroke patients [39]. This is the case of barium in the present study (Table 2). Barium is a compound frequently used in medical tests as a contrast, which makes it necessary to know details of the clinical history that were not considered in the present study. To our knowledge, this is the first time that any type of association between barium and stroke has been observed. However, this is a modest result that would require further investigation in larger series to elucidate the mechanism of action behind this association.

\subsection{REEs and Other Inorganic Elements in Stroke}

A total of 26 rare earth elements (RREs) and other elements used in the manufacturing of high tech devices [15] were analyzed in the whole blood of cases and controls. Cerium, iron and gallium were detected in $100 \%$ of subjects (Table 4). Lutetium, tantalum, terbium and thulium were detected in less than $15 \%$ of cases and/or controls. We did not observe any influence of age in relation to the blood concentration of these elements among controls. However, we observed a positive correlation of some of these elements with age among cases (Supplementary Materials 2): dysprosium (Pearson's $r=0.26, p$-value $=0.013$ ), erbium (Pearson's $r=0.30, p$-value $=0.003$ ), europium (Pearson's $r=0.25, p$-value $=0.014)$, holmium (Pearson's $r=0.29, p$-value $=0.005)$, neodymium (Pearson's $r=0.28, p$-value $=0.008$ ), praseodymium (Pearson's $r=0.24, p$-value $=0.020$ ), thulium (Pearson's $r=0.23, p$-value $=0.024)$, yttrium (Pearson's $r=0.23, p$-value $=0.027$ ) and ytterbium (Pearson's $r=0.26$, $p$-value $=0.014$ ). Blood concentration of iron was significantly lower among women, in cases and controls $(270.4$ vs. $292.4 \mathrm{ng} / \mathrm{mL}, p$-value $=0.002 ; 264.3$ vs. $301.1 \mathrm{ng} / \mathrm{mL}$, $p$-value $=0.004$; respectively). We did not detect significant differences between RREs and clinical variables (Supplementary Materials 3). 
Table 4. Blood concentration (ng/mL) of rare earth elements (REE) and elements used in high tech devices ${ }^{\text {a }}$, among cases and controls.

\begin{tabular}{|c|c|c|c|c|c|c|c|}
\hline & \multicolumn{3}{|c|}{ Controls $(n=83)$} & \multicolumn{3}{|c|}{ Cases $(n=92)$} & \multirow[b]{2}{*}{$p$-Value } \\
\hline & Frequency of Detection (\%) & Median & (p5th-p95th) & Frequency of Detection (\%) & Median & (p5th-p95th) & \\
\hline $\mathrm{Au}$ (gold) & 57.8 & 0.013 & $(0.001-0.80)$ & 30.4 & 0.007 & $(0-0.28)$ & 0.001 \\
\hline Bi (bismuth) & 86.7 & 0.11 & $(0.001-0.33)$ & 63.0 & 0.085 & $(0-0.16)$ & 0.001 \\
\hline Ce (cerium) & 100 & 18.0 & $(8.02-81.7)$ & 100 & 15.0 & $(7.23-47.2)$ & 0.010 \\
\hline Dy (dysprosium) & 86.7 & 0.017 & $(0-0.062)$ & 84.8 & 0.018 & $(0-0.037)$ & 0.459 \\
\hline Er (erbium) & 57.8 & 0.002 & $(0-0.027)$ & 41.3 & 0 & $(0-0.015)$ & 0.806 \\
\hline Eu (europium) & 45.8 & 0 & $(0-0.022)$ & 58.7 & 0.007 & $(0-0.017)$ & 0.047 \\
\hline $\mathrm{Fe}$ (iron) ${ }^{\mathrm{c}, \mathrm{d}}$ & 100 & 275.5 & $(187.6-427.6)$ & 100 & 277.8 & $(203.4-357.9)$ & 0.860 \\
\hline Ga (gallium) & 100 & 0.61 & $(0.27-4.47)$ & 100 & 0.49 & $(0.20-1.58)$ & 0.014 \\
\hline Gd (gadolinium) & 69.9 & 0.036 & $(0-0.15)$ & 63.0 & 0.032 & $(0-0.089)$ & 0.207 \\
\hline Ho (holmium) & 26.5 & 0 & $(0-0.010)$ & 43.5 & 0 & $(0-0.007)$ & 0.079 \\
\hline In (indium) & 20.5 & 0 & $(0-0.035)$ & 64.1 & 0.001 & $(0-0.040)$ & 0.000 \\
\hline La (lanthanum) & 47.0 & 0.010 & $(0.002-0.30)$ & 22.8 & 0.007 & $(0-0.28)$ & 0.002 \\
\hline Lu (lutetium) & 12.0 & 0 & $(0-0.003)$ & 7.6 & 0 & $(0-0.002)$ & 0.425 \\
\hline $\mathrm{Nb}$ (niobium) & 49.4 & 0.014 & $(0.001-0.58)$ & 29.3 & 0.011 & $(0.001-0.57)$ & 0.159 \\
\hline Nd (neodymium) & 53.0 & 0.006 & $(0.001-0.28)$ & 50.0 & 0.005 & $(0.001-0.22)$ & 0.275 \\
\hline Os (osmium) & 81.9 & 0.002 & $(0-0.023)$ & 66.3 & 0.001 & $(0-0.053)$ & 0.000 \\
\hline $\operatorname{Pr}$ (praseodymium) & 48.2 & 0.001 & $(0-0.070)$ & 50.0 & 0.002 & $(0-0.051)$ & 0.727 \\
\hline $\mathrm{Pt}$ (platinum) & 30.1 & 0 & $(0-0.014)$ & 45.7 & 0 & $(0-0.010)$ & 0.001 \\
\hline $\mathrm{Ru}$ (ruthenium) & 60.2 & 0.001 & $(0-0.002)$ & 22.8 & 0 & $(0-0.002)$ & 0.000 \\
\hline Sm (samarium) & 83.1 & 0.001 & $(0-0.067)$ & 79.3 & 0.001 & $(0-0.045)$ & 0.109 \\
\hline Sn (tin) & 54.2 & 0.17 & $(0.017-4.16)$ & 42.4 & 0.11 & $(0.018-8.58)$ & 0.680 \\
\hline $\mathrm{Ta}$ (tantalum) & 9.6 & 0.003 & $(0.001-0.28)$ & 8.7 & 0.004 & $(0.001-0.35)$ & 0.107 \\
\hline $\mathrm{Tb}$ (terbium) & 22.9 & 0 & $(0-0.014)$ & 8.7 & 0 & $(0-0.009)$ & 0.410 \\
\hline Tm (thulium) & 3.6 & 0 & $(0-0.003)$ & 19.6 & 0 & $(0-0.003)$ & 0.009 \\
\hline Y (yttrium) & 54.2 & 0.004 & $(0-0.26)$ & 56.5 & 0.004 & $(0-0.17)$ & 0.756 \\
\hline $\mathrm{Yb}$ (ytterbium) & 19.3 & 0 & $(0-0.015)$ & 26.1 & 0 & $(0-0.012)$ & 0.001 \\
\hline
\end{tabular}

Abbreviations: p5th-p95th percentiles 5 and 95 of the distribution. ${ }^{a}$ Complete list available from B. Tansel et al. Environment International 98 (2017) 35-45. ${ }^{b}$ Mann-Whitney U test (two tails). Significant differences are highlighted in bold. ${ }^{c}$ Also considered as trace elements. ${ }^{d}$ Data reported in $\mu \mathrm{g} / \mathrm{mL}$. 
Of the 26 RREs, 12 showed a statistically different blood concentration between cases and controls. However, trying to guarantee a minimum statistical power, only elements with detection frequencies higher than $80 \%$ were considered. Thus, blood concentration of bismuth, cerium, gallium and osmium were higher among controls (Table 4). In univariate analysis, cerium and gallium showed an association with stroke (Table 3). No significant results were observed for bismuth and osmium (data not shown). In multivariate analysis, cerium and gallium kept their significant tendency (Table 3), which suggests that, apart from the ability to cross the blood-brain barrier [18], these elements could play a protective effect on stroke. The effect that gallium may have on stroke is difficult to assess since it is usually used as a contrast in various medical tests. It is necessary to know details of the clinical history to be able to discriminate the true effect of the association observed in the present study.

The role of these minority elements seems to be more important than initially thought. Thus, it has been recently published that gold nanoclusters penetrate the blood-brain barrier and have neuroprotective effects, suggesting the possibility of utilizing this nanoparticles to regulate microglial polarization and improve neuronal regeneration in central nervous system [46]. In the present study, blood concentration of gold was significantly higher among controls (Table 4) and the association with stroke was also found in multivariate analysis (Table 3). Although the frequency of detection of gold did not meet the quality standards imposed to guarantee a minimum statistical power, the present result agrees with others which suggest that gold is an interesting factor to consider for the treatment of stroke [46]. The neuroprotective role of cerium has been previously reported $[47,48]$. Cerium oxide nanoparticles, known as nanoceria, show a promising potential in diverse disorders such as stroke. The mechanism behind this effect is closely related to the antioxidant capacity of these particles [49]. Thus, the neuroprotective effects of nanoceria are due to a modest reduction in reactive oxygen species and to a reduction of the levels of ischemia-induced 3-nitrotyrosine, a modification to tyrosine residues in proteins induced by the peroxynitrite radical [47]. Optimal doses of nanoceria reduce infarct volumes and the rate of ischemic cell death $[48,49]$ and may be useful as a therapeutic intervention to reduce oxidative and nitrosative damage after a stroke [47]. The findings observed in this regard in our series may contribute to improve the knowledge about the role of gold and cerium in relation to stroke.

\subsection{Strengths and Limitations of the Study}

The present study is a case control study aimed to evaluate the role of inorganic elements in stroke. One of the main limitations for this type of studies is the design of the groups. In that sense, we tried to minimize the impact of non-modifiable risk factors for stroke. Thus, gender and age were comparable among cases and controls. However, modifiable risk factors were different between groups, which suppose a bias that must be taken into account when interpreting the results. Ideally, the control group should exclude patients with hypertension, dyslipidemia, smokers and other obvious risk factors for stroke. Despite this, the fact that the main results were not influenced by these types of factors lends credibility to them. Sample size is a clear limitation in this type of studies. Our series included 92 cases and 83 controls, a modest number that can limit the statistical confidence. However, while it is true that similar studies have been done with a greater number of patients, other studies included smaller patient groups [39]. In any case, we tried to increase the statistical confidence by performing multivariate analysis - taken into account cofounding variables-, elements were included in the analyses after log transformation and we considered elements that showed high detection frequencies ( $>80 \%$ ). However, we are aware that variables such as diet, details about smoking habit (intensity, duration type of tobacco and even label, which could be a significant source of inorganic elements [36]), other toxic habits like alcohol or illicit drugs intake, clinical endpoints associated with stroke (medical tests and other clinical variables like blood pressure), pharmacological treatments (antihypertensive drugs among controls) and other variables related with lifestyle (sedentary lifestyle) were avoided and could be of relevance. Similarly, we do not know the combined effect that these elements may have on human health, especially considering that exposure to many of these elements 
correlates with exposure to others [45]. We observed a significant amount of correlations between the elements, most of them positive (Supplementary Materials 4). Moreover, the patterns of correlation appeared to be different in cases and controls (Supplementary Materials 4, see correlation maps), suggesting the existence of different exposure profiles [37,50]. This finding is similar to previous published studies [45,50] and encourage exploring the combined action of contaminants. Finally, due to the characteristics of the study design, the mechanism of action behind our results can only be hypothesized. Therefore, the present study should be considered as a hypothesis generator.

According to the analyses carried out, the series seems robust both in its conformation and in its distribution, which gives value to the observed results. The methodology is equally robust and has been validated in previous studies [29]. Finally, to our knowledge, it is the first time that such a quantity of inorganic elements is measured in relation to this disease, which can contribute to broadening knowledge about a disease of such wide distribution and mortality.

\section{Conclusions}

Our study was the first to evaluate a large amount of inorganic elements in relation to stroke, including 19 inorganic elements belonging to the ATSDR's priority pollutant list and 26 rare earth elements and other elements used in the manufacturing of high tech devices. The findings of this study indicated that patients with stroke had higher levels of lead and lower levels of bismuth, cerium, gallium and osmium. These findings provided new evidence of the potential association of dysregulated heavy metals and other elements in patients with stroke, whose ability to cross the blood brain barrier has been previously suggested. While lead was as a risk factor for stroke, barium, gold, cerium and gallium appeared as protective factors for the disease. Given the high persistence of these elements in the environment and the significant technological dependence on them, future studies are needed to elucidate the potential sources of exposure and disclose the mechanisms of action of the identified elements in the prevalence and prognosis of stroke.

Supplementary Materials: The following are available online at http:/www.mdpi.com/2305-6304/8/3/66/s1. Supplementary material 1: Limit of quantification (LOQ)a of elements of inorganic elements included in the study, Supplementary material 2: Bivariate correlations between inorganic elements and continuous demographic variables, Supplementary material 3: Bivariate correlations between inorganic elements and categorical variables. Significant associations are highlighted in bold. Data reported in ng/mL, except for copper, zinc and iron (ug/mL), Supplementary material 4a: Bivariate Spearman correlations between the inorganic elements among controls $(n=83)$, Supplementary material $4 \mathrm{~b}$ : Bivariate Spearman correlations between the inorganic elements among cases $(n=92)$.

Author Contributions: Conceptualization, F.M.-E., L.D.B. and L.A.H.-H.; methodology, M.Z. and Á.R.-H. formal analysis, L.A.H.-H.; data curation, F.M.-E., F.F.-F. and M.E.S.-J.; writing-original draft preparation, L.A.H.-H.; writing-review and editing, O.P.L. and L.D.B.; supervision, O.P.L.; project administration, L.D.B. All authors have read and agreed to the published version of the manuscript.

Funding: This research received no external funding.

Acknowledgments: The authors would also like to thank all participants, without whom this study would not have been possible.

Conflicts of Interest: The authors declare that they have no competing interests.

\section{References}

1. WSO. Global Stroke Fact Sheet. 2016. Available online: https://www.world-stroke.org/assets/downloads/ WSO_Global_Stroke_Fact_Sheet.pdf (accessed on 20 August 2020).

2. Guzik, A.; Bushnell, C. Stroke Epidemiology and Risk Factor Management. Continuum. (Minneap. Minn.) 2017, 23, 15-39. [CrossRef] [PubMed]

3. SCS. Guía de Atención al Ictus; Asistenciales, D.G.d.P., Ed.; Servicio Canario de la Salud (SCS): Canary Islands, Spain, 2013.

4. Thrift, A.G.; Thayabaranathan, T.; Howard, G.; Howard, V.J.; Rothwell, P.M.; Feigin, V.L.; Norrving, B.; Donnan, G.A.; Cadilhac, A.D. Global stroke statistics. Int. J. Stroke 2017, 12, 13-32. [CrossRef] [PubMed] 
5. Johnson, W.; Onuma, O.; Owolabi, M.; Sachdev, S. Stroke: A global response is needed. Bull. World Health Organ. 2016, 94, 634. [CrossRef] [PubMed]

6. SNS. Estrategia en Ictus del Sistema Nacional de Salud; Ministerio de Sanidad y Política Social: Madrid, Spain, 2009.

7. Boehme, A.K.; Esenwa, C.; Elkind, M.S. Stroke Risk Factors, Genetics, and Prevention. Circ. Res. 2017, 120, 472-495. [CrossRef] [PubMed]

8. Shah, A.S.; Lee, K.K.; McAllister, D.A.; Hunter, A.; Nair, H.; Whiteley, W.; Langrish, J.P.; Newby, D.E.; Mills, N.L. Short term exposure to air pollution and stroke: Systematic review and meta-analysis. BMJ 2015, 350, h1295. [CrossRef]

9. Lee, D.H.; Lind, P.M.; Jacobs, D.R., Jr.; Salihovic, S.; van Bavel, B.; Lind, L. Background exposure to persistent organic pollutants predicts stroke in the elderly. Environ. Int. 2012, 47, 115-120. [CrossRef]

10. Lim, J.E.; Lee, S.; Jee, S.H. Serum persistent organic pollutants levels and stroke risk. Environ. Pollut. 2018, 233, 855-861. [CrossRef]

11. Henriquez-Hernandez, L.A.; Luzardo, O.P.; Zumbado, M.; Camacho, M.; Serra-Majem, L.; Alvarez-Leon, E.E.; Boada, L.D. Blood pressure in relation to contamination by polychlorobiphenyls and organochlorine pesticides: Results from a population-based study in the Canary Islands (Spain). Environ. Res. 2014, 135, 48-54. [CrossRef]

12. Henriquez-Hernandez, L.A.; Luzardo, O.P.; Zumbado, M.; Serra-Majem, L.; Valeron, P.F.; Camacho, M.; Alvarez-Perez, J.; Salas-Salvado, J.; Boada, L.D. Determinants of increasing serum POPs in a population at high risk for cardiovascular disease. Results from the PREDIMED-CANARIAS study. Environ. Res. 2017, 156, 477-484. [CrossRef]

13. Henriquez-Hernandez, L.A.; Luzardo, O.P.; Valeron, P.F.; Zumbado, M.; Serra-Majem, L.; Camacho, M.; Gonzalez-Antuna, A.; Boada, L.D. Persistent organic pollutants and risk of diabetes and obesity on healthy adults: Results from a cross-sectional study in Spain. Sci. Total Environ. 2017, 607-608, 1096-1102. [CrossRef]

14. Hussain, M.; Mumtaz, S. E-waste: Impacts, issues and management strategies. Rev. Environ. Health 2014, 29, 53-58. [CrossRef] [PubMed]

15. Tansel, B. From electronic consumer products to e-wastes: Global outlook, waste quantities, recycling challenges. Environ. Int. 2017, 98, 35-45. [CrossRef] [PubMed]

16. Bozlaker, A.; Prospero, J.M.; Fraser, M.P.; Chellam, S. Quantifying the contribution of long-range Saharan dust transport on particulate matter concentrations in Houston, Texas, using detailed elemental analysis. Environ. Sci. Technol. 2013, 47, 10179-10187. [CrossRef] [PubMed]

17. Pagano, G.; Aliberti, F.; Guida, M.; Oral, R.; Siciliano, A.; Trifuoggi, M.; Tommasi, F. Rare earth elements in human and animal health: State of art and research priorities. Environ. Res. 2015, 142, 215-220. [CrossRef] [PubMed]

18. Gaman, L.; Radoi, M.P.; Delia, C.E.; Luzardo, O.P.; Zumbado, M.; Rodriguez-Hernandez, A.; Stoian, I.; Gilca, M.; Boada, L.D.; Henriquez-Hernandez, L.A. Concentration of heavy metals and rare earth elements in patients with brain tumours: Analysis in tumour tissue, non-tumour tissue, and blood. Int. J. Environ. Health Res. 2019, 1-14. [CrossRef] [PubMed]

19. Henriquez-Hernandez, L.A.; Boada, L.D.; Carranza, C.; Perez-Arellano, J.L.; Gonzalez-Antuna, A.; Camacho, M.; Almeida-Gonzalez, M.; Zumbado, M.; Luzardo, O.P. Blood levels of toxic metals and rare earth elements commonly found in e-waste may exert subtle effects on hemoglobin concentration in sub-Saharan immigrants. Environ. Int. 2017, 109, 20-28. [CrossRef] [PubMed]

20. Cabrera-Rodriguez, R.; Luzardo, O.P.; Gonzalez-Antuna, A.; Boada, L.D.; Almeida-Gonzalez, M.; Camacho, M.; Zumbado, M.; Acosta-Dacal, A.C.; Rial-Berriel, C.; Henriquez-Hernandez, L.A. Occurrence of 44 elements in human cord blood and their association with growth indicators in newborns. Environ. Int. 2018, 116, 43-51. [CrossRef]

21. Pagano, G.; Guida, M.; Tommasi, F.; Oral, R. Health effects and toxicity mechanisms of rare earth elements-Knowledge gaps and research prospects. Ecotoxicol. Environ. Saf. 2015, 115, 40-48. [CrossRef]

22. Tsinovoi, C.L.; Xun, P.; McClure, L.A.; Carioni, V.M.O.; Brockman, J.D.; Cai, J.; Guallar, E.; Cushman, M.; Unverzagt, F.W.; Howard, V.J.; et al. Arsenic Exposure in Relation to Ischemic Stroke: The Reasons for Geographic and Racial Differences in Stroke Study. Stroke 2018, 49, 19-26. [CrossRef] 
23. Moon, K.A.; Oberoi, S.; Barchowsky, A.; Chen, Y.; Guallar, E.; Nachman, K.E.; Rahman, M.; Sohel, N.; D'Ippoliti, D.; Wade, T.J.; et al. A dose-response meta-analysis of chronic arsenic exposure and incident cardiovascular disease. Int. J. Epidemiol. 2017, 46, 1924-1939. [CrossRef]

24. Steenland, K.; Barry, V.; Anttila, A.; Sallmen, M.; McElvenny, D.; Todd, A.C.; Straif, K. A cohort mortality study of lead-exposed workers in the USA, Finland and the UK. Occup. Environ. Med. 2017, 74, 785-791. [CrossRef] [PubMed]

25. Chiou, H.Y.; Huang, W.I.; Su, C.L.; Chang, S.F.; Hsu, Y.H.; Chen, C.J. Dose-response relationship between prevalence of cerebrovascular disease and ingested inorganic arsenic. Stroke 1997, 28, 1717-1723. [CrossRef] [PubMed]

26. Tchounwou, P.B.; Yedjou, C.G.; Patlolla, A.K.; Sutton, D.J. Heavy metal toxicity and the environment. Exp. Suppl. 2012, 101, 133-164. [PubMed]

27. Cid-Ruzafa, J.; Damian-Moreno, J. Disability evaluation: Barthel's index. Rev. Esp. Salud. Publica 1997, 71, 127-137. [CrossRef] [PubMed]

28. ATSDR. Agency for Toxic Substances and Disease Registry. 2018. Available online: https://www.atsdr.cdc.gov/ (accessed on 27 January 2020).

29. Gonzalez-Antuna, A.; Camacho, M.; Henriquez-Hernandez, L.A.; Boada, L.D.; Almeida-Gonzalez, M.; Zumbado, M.; Luzardo, O.P. Simultaneous quantification of 49 elements associated to e-waste in human blood by ICP-MS for routine analysis. MethodsX 2017, 4, 328-334. [CrossRef]

30. Lubin, J.H.; Colt, J.S.; Camann, D.; Davis, S.; Cerhan, J.R.; Severson, R.K.; Bernstein, L.; Hartge, P. Epidemiologic evaluation of measurement data in the presence of detection limits. Environ. Health Perspect. 2004, 112, 1691-1696. [CrossRef]

31. Orozco-Beltran, D.; Sanchez, E.; Garrido, A.; Quesada, J.A.; Carratala-Munuera, M.C.; Gil-Guillen, V.F. Trends in Mortality From Diabetes Mellitus in Spain: 1998-2013. Rev. Esp. Cardiol. (Engl. Ed.) 2017, 70, 433-443. [CrossRef]

32. Wolf, P.A.; D'Agostino, R.B.; Belanger, A.J.; Kannel, W.B. Probability of stroke: A risk profile from the Framingham Study. Stroke 1991, 22, 312-318. [CrossRef]

33. Musa, K.I.; Keegan, T.J. The change of Barthel Index scores from the time of discharge until 3-month post-discharge among acute stroke patients in Malaysia: A random intercept model. PLoS ONE 2018, 13, e0208594. [CrossRef]

34. Furst, A. Can nutrition affect chemical toxicity? Int. J. Toxicol. 2002, 21, 419-424. [CrossRef]

35. Starling, P.; Charlton, K.; McMahon, A.T.; Lucas, C. Fish intake during pregnancy and foetal neurodevelopment-A systematic review of the evidence. Nutrients 2015, 7, 2001-2014. [CrossRef] [PubMed]

36. Zumbado, M.; Luzardo, O.P.; Rodriguez-Hernandez, A.; Boada, L.D.; Henriquez-Hernandez, L.A. Differential exposure to 33 toxic elements through cigarette smoking, based on the type of tobacco and rolling paper used. Environ. Res. 2019, 169, 368-376. [CrossRef] [PubMed]

37. Badea, M.; Luzardo, O.P.; Gonzalez-Antuna, A.; Zumbado, M.; Rogozea, L.; Floroian, L.; Alexandrescu, D.; Moga, M.; Gaman, L.; Radoi, M.; et al. Body burden of toxic metals and rare earth elements in non-smokers, cigarette smokers and electronic cigarette users. Environ. Res. 2018, 166, 269-275. [CrossRef] [PubMed]

38. Mezynska, M.; Brzoska, M.M. Environmental exposure to cadmium-a risk for health of the general population in industrialized countries and preventive strategies. Environ. Sci. Pollut. Res. Int. 2018, 25, 3211-3232. [CrossRef] [PubMed]

39. Lin, C.H.; Hsu, Y.T.; Yen, C.C.; Chen, H.H.; Tseng, C.J.; Lo, Y.K.; Chan, J.Y.H. Association between heavy metal levels and acute ischemic stroke. J. Biomed. Sci. 2018, 25, 49. [CrossRef] [PubMed]

40. Wang, B.; Zhu, Y.; Pang, Y.; Xie, J.; Hao, Y.; Yan, H.; Li, Z.; Ye, R. Indoor air pollution affects hypertension risk in rural women in Northern China by interfering with the uptake of metal elements: A preliminary cross-sectional study. Environ. Pollut. 2018, 240, 267-272. [CrossRef]

41. Chowdhury, R.; Ramond, A.; O’Keeffe, L.M.; Shahzad, S.; Kunutsor, S.K.; Muka, T.; Gregson, J.; Willeit, P.; Warnakula, S.; Khan, H.; et al. Environmental toxic metal contaminants and risk of cardiovascular disease: Systematic review and meta-analysis. BMJ 2018, 362, k3310. [CrossRef]

42. Wen, Y.; Huang, S.; Zhang, Y.; Zhang, H.; Zhou, L.; Li, D.; Xie, C.; Lv, Z.; Guo, Y.; Ke, Y.; et al. Associations of multiple plasma metals with the risk of ischemic stroke: A case-control study. Environ. Int. 2019, 125, 125-134. [CrossRef] 
43. Wang, W.; Liu, C.; Ying, Z.; Lei, X.; Wang, C.; Huo, J.; Zhao, Q.; Zhang, Y.; Duan, Y.; Chen, R.; et al. Particulate air pollution and ischemic stroke hospitalization: How the associations vary by constituents in Shanghai, China. Sci. Total Environ. 2019, 695, 133780. [CrossRef]

44. Saravanabhavan, G.; Werry, K.; Walker, M.; Haines, D.; Malowany, M.; Khoury, C. Human biomonitoring reference values for metals and trace elements in blood and urine derived from the Canadian Health Measures Survey 2007-2013. Int. J. Hyg. Environ. Health 2017, 220, 189-200. [CrossRef]

45. Henriquez-Hernandez, L.A.; Romero, D.; Gonzalez-Antuna, A.; Gonzalez-Alzaga, B.; Zumbado, M.; Boada, L.D.; Hernandez, A.F.; Lopez-Flores, I.; Luzardo, O.P.; Lacasana, M. Biomonitoring of 45 inorganic elements measured in plasma from Spanish subjects: A cross-sectional study in Andalusian population. Sci. Total Environ. 2020, 706, 135750. [CrossRef] [PubMed]

46. Xiao, L.; Wei, F.; Zhou, Y.; Anderson, G.J.; Frazer, D.M.; Lim, Y.C.; Liu, T.; Xiao, Y. Dihydrolipoic Acid-Gold Nanoclusters Regulate Microglial Polarization and Have the Potential to Alter Neurogenesis. Nano Lett. 2020, 20, 478-495. [CrossRef] [PubMed]

47. Estevez, A.Y.; Pritchard, S.; Harper, K.; Aston, J.W.; Lynch, A.; Lucky, J.J.; Ludington, J.S.; Chatani, P.; Mosenthal, W.P.; Leiter, J.C.; et al. Neuroprotective mechanisms of cerium oxide nanoparticles in a mouse hippocampal brain slice model of ischemia. Free Radic. Biol. Med. 2011, 51, 1155-1163. [CrossRef] [PubMed]

48. Kim, C.K.; Kim, T.; Choi, I.Y.; Soh, M.; Kim, D.; Kim, Y.J.; Jang, H.; Yang, H.S.; Kim, J.Y.; Park, H.K.; et al. Ceria nanoparticles that can protect against ischemic stroke. Angew. Chem. Int. Ed. Engl. 2012, 51, 11039-11043. [CrossRef]

49. Zhou, D.; Fang, T.; Lu, L.Q.; Yi, L. Neuroprotective potential of cerium oxide nanoparticles for focal cerebral ischemic stroke. J. Huazhong Univ. Sci. Technolog. Med. Sci. 2016, 36, 480-486. [CrossRef]

50. Hou, Q.; Huang, L.; Ge, X.; Yang, A.; Luo, X.; Huang, S.; Xiao, Y.; Jiang, C.; Li, L.; Pan, Z.; et al. Associations between multiple serum metal exposures and low birth weight infants in Chinese pregnant women: A nested case-control study. Chemosphere 2019, 231, 225-232. [CrossRef]

(C) 2020 by the authors. Licensee MDPI, Basel, Switzerland. This article is an open access article distributed under the terms and conditions of the Creative Commons Attribution (CC BY) license (http://creativecommons.org/licenses/by/4.0/). 